\title{
SOME ADMINISTRATIVE MEASURES TAKEN AGAINST MALARIA AND CONSUMPTION IN THE TROPICS.
}

\author{
By SIR RICHARD C. TEMPLE, Bart., C.I.E.,
}

Late Chief Commissioner, Andaman and Nicobar Islands.

\section{ABSTRACT.}

THE Andaman Islands are situated in the Bay of Bengal and are thoroughly tropical. They are hilly, naturally covered with jungle, and surrounded with mangrove swamp and coral reef shores. The Penal Settlement of Port Blair is situated in and about a large harbour in the South Andaman Island. The inhabitants of the Penal Settlement occupy the harbour, islands in it, and about 300 square miles round it, partly cleared and partly forest. The rainfall varies from 130 to 200 inches per annum in parts, and the crops are chiefly "rain crops." The islands are a home of the mosquito, and malaria is much the most common disease.

The population consists of convicts and those over and connected with them. There are from 12,000 to 13,000 convicts and 4,000 others, of whom 1,400 are children. They are scattered over the whole settlement in convict stations and in villages. The bulk of them are under a strict discipline, and all are under Government control. Of late years administrative measures have been taken to control the spread of malaria and also of consumption (phthisis and tuberculosis) among this population.

Convict health statistics must be read with caution, owing to Government interference with the natural course of diseases, but nevertheless Port Blair statistics show that monthly rainfall does affect the sick rates, these being much the highest during the rains; and that acclimatisation greatly affects them also, the new arrivals chiefly filling the sick-rate tables. Malaria (47 per cent.), with consequent dysentery ( 7 per cent.), accounts for 54 per cent. of the sickness in the place. Consumption accounts for 6 per cent., and is steadily increasing. It was with regard to checking malaria, dysentery, and consumption that special experimental administrative measures were taken in 1902 onwards. 


\section{Administrative Measures against Malaria and Consumption.}

In 1867 an important medical report was made, showing the great preponderance of fevers as a general cause of sickness, and, incidentally, that keeping a small island clean and cleared of excessive vegetation resulted in the fact that the fever-rate was there lower than that of the other diseases. This was attributed to the absence of miasma, though it would now be attributed to giving small opportunity for mosquitoes to breed.

The steps taken in 1902 were, first, to ascertain the simplest and cheapest methods locally applicable to prevent mosquitoes from breeding, and then to create a strong convict mosquito brigade at all convict stations, to define its work in detail, to instruct the members, and to provide them with suitable tools. Free residents were shown how they could help. These steps had a general as well as a special sanitary value. A village mosquito brigade of ticliet-of-leave convicts was also organised to meet special requirements, every member was instructed in his duties, which were defined in detail, and he was encouraged and supervised in his work. The result ensured general cleanliness.

The ceaseless arrival of fresh convicts from India prevents the effects of such measures from being quickly apparent, and the author left before they could be seen, but in the smaller islands mosquitoes were sensibly reduced in numbers in a very short time.

As from ignorance the convicts proved to be very slow to perceive the advantages of sanitation, and offered passive resistance to all improvements, advantage was taken of the ambulance and first aid training established amongst them to educate them in the nature of malaria and consumption, in simple means for combatting them and in elementary sanitation, with much success, though with much labour on the part of the medical authorities.

Among the experiments tried against malaria was the netting in of some barracks in the female jail, which created a difficulty, as the nets excluded both air and mosquitoes, and so tended to promote the spread of consumption.

The question was very carefully discussed at Port Blair, and finally submitted to the Government of India for decision shortly before the author's retirement, and the decision, if any, is not known to him; but the advice he gave as the result of the local discussion was briefly this. That consumption could be best met by additional sleeping floor space in the barracks, more changes of clothing in view of the unavoidable exposure to damp and rain, additional establishment for medical inspection and weighment of convicts to ensure early detection of the disease. To check malaria he advised mosquito brigades as of great general sanitary value, 
and the use of quinine as a prophylactic, in addition to the remedies that applied equally in the case of consumption. To check the dysentery, as being "institution dysentery," he advised segregation on detection. What action has been or will be taken on this advice he does not know. $\mathrm{He}$ also advised that in the conditions of Port Blair that mosquito netting be abandoned, as the brigades were a sufficient remedy.

The points of interest for the Congress in these experiments appear to be :-

(1) Malaria is an overwhelming cause of incapacity for work and of death in the tropics.

(2) A place like the Port Blair Penal Settlement affords exceptional opportunities for experimental administrative measures for combatting it.

(3) The presence of malaria and consumption in the same locality as dominating dangerous diseases (the usual dangerous Oriental epidemics, like cholera, typhoid, plague, small-pox, beri-beri, are absent from the Penal Settlement) presents a difficulty in dealing effectively with malaria on existing theories and practice which requires full consideration.

Sir R. Dodth.Ls Poweld (London) observed that there was not much room for comment on Sir Ricbard Temple's paper. The author was, however, to be congratulated upon bis success under difficult circumstances, for the people among whom he had introduced his system of working were exceedingly hard to manage. The difficulty was perhaps overcome by the wide control and disciplinary powers which the author had possessed as Governor of the island, but a greater difficulty remained in the fact that he had to combat two diseases that called for different forms of treatment : malarial fever and tuberculosis. The modern view regarding the communication of malarial fevers and how best to combat them demanded that mosquitoes should be prevented from gaining access to the victims, and this was best effected by means of mosquito nets and similar devices. But, as Sir Richard had told them, this was accompanied by the disadvantage of an insufficient supply of fresh air, for, as they well bnew, even the thinnest gauze placed over a window was apt to render the air of a room stagnant. The consequence was that as malarial ferer diminished there was a tendency for tubercular infection to increase. He was therefore of opinion that it was right to revert to more general measures by improving the surroundings and by removing all filth, and in that way to destroy the breeding grounds, not merely of the mosquitoes, but also of the tubercle bacillus, or at least of those places where the bacillus might be supposed to enjoy itself when not in the human organism. Unfortunately, Sir Richard Temple had not been able to give his results in a completed form, as he had left before the experiments were concluded. As 


\section{Administrative Measures against Malaria and Consumption.}

would have been observed, there were great fluctuations in the death-rates of the different periods referred to in the paper, and it would be interesting to know whether there was any relationship between those fluctuations and the rainy seasons, or whether it was possible to explain them in any other way. What was required was periodic publication by the India Office of the results of such experiments, and with the view of obtaining that publication be proposed: "That in view of the fact that the Penal Settlement at Port Blair affords exceptional opportunities for effective experimental measures for checking the spread of malaria and consumption, it is recommended that the Council of The Sanitary Institute represent to the Government of India the value of communicating from time to time the results of the experiments inaugurated there in 1902."

Mr. A. Wenkes (East Sussex C.C.) said (as to the causes of the great fluctuations in the death-rates referred to by Sir Douglas Powell) he might offer a probable explanation. During the years 1871, 1872, 1873, and 1874, when the death-rate was very low, there occurred the Bengal famine, when the monsoon failed for two seasons, and the Andaman Islands, being in the line of the monsoons, also suffered; so that when there was a deficient rainfall, and many pools and rice fields were dry, there were fewer breeding places for the mosquitoes, and then at all events they were not so prevalent as in normal years. Curiously enough, the only other low death-rate, vi\%., that for the period ending 1857 , corresponded with the time antecedent to the great Madras famine. When he was in India the connection of malaria with the mosquito was unknown, but he used always to associate malaria with rainfall, and particularly with the stagnant rice fields, which are the great breeding grounds of this particular pest.

Sir Rrchurd Trmpee, in thanking the Conference and Sir Douglas Powell, said that he placed more importance upon the results of the experiments which he had carried out from the fact that, as Administrator of the Islands, he had possessed complete disciplinary powers over practically the entire population. As to the question of the supposed connection between the wide fluctuations in the death-rate and the rainfall at different periods, he bad been collecting statistics bearing on these points for some time, but was not satisfied that any definite conclusion could be arrived at. It was quite true that during the period 1871 to 1874 there had been a small rainfall, but in the period ending 1882 there had been a low fever rate and a high rainfall. On the whole, he did not consider that the rainfall had any great influence upon the fever death-rate.

The President (Prof. Glaister) also took part in the discussion. 